\title{
Ovarian torsion in infertility treatment
}

\author{
Yaramareddy Swapna $^{1}$, M. Elanchezhian ${ }^{1 *}$, Supraja Chegireddy ${ }^{2}$, \\ Raju Badipati $^{3}$, V. Devadharshini ${ }^{1}$
}

\begin{abstract}
${ }^{1}$ Komali Fertility Centre-A Unit of Ramesh Cardiac and Multispecialty Hospitals, Guntur, Andhra Pradesh, India ${ }^{2}$ Department of Radiology, Ramesh Cardiac and Multispecialty Hospitals, Guntur, Andhra Pradesh, India ${ }^{3}$ Department of General and Laparoscopic Surgery, Ramesh Cardiac and Multispecialty Hospitals, Guntur, Andhra Pradesh, India
\end{abstract}

Received: 25 November 2020

Accepted: 29 December 2020

\author{
*Correspondence: \\ M. Elanchezhian, \\ E-mail: avarnan.che@gmail.com
}

Copyright: () the author(s), publisher and licensee Medip Academy. This is an open-access article distributed under the terms of the Creative Commons Attribution Non-Commercial License, which permits unrestricted non-commercial use, distribution, and reproduction in any medium, provided the original work is properly cited.

\begin{abstract}
Ovarian torsion, a rare problem in women can lead to serious consequences if not diagnosed and treated at the earliest. It is one of the complications that needs to be included in the differential diagnosis of any girl with abdominal pain or a pelvic or abdominal mass as the symptoms and signs are nonspecific and it can be related to other clinical causes. A 29-year-old woman who was under ovulation induction was diagnosed with ovarian torsion which was treated by performing laparoscopy. Investigations for ovarian torsion should be carried out for all the patients treated for infertility presenting with abdominal pain to minimize the risk before it is too late.
\end{abstract}

Keywords: Ovarian Torsion, Clomiphene, Laparoscopy, Infertility, Adnexal mass

\section{INTRODUCTION}

Ovarian torsion is a rare problem in the paediatric age group that involves the tube, ovary and ancillary structures. ${ }^{1,2}$ It is defined as the total or partial rotation of the adnexal around its vascular axis. ${ }^{3}$ It leads first to lymphatic and venous congestion and then to the arterial blood supply becoming compromised, which in turn results in tissue necrosis or thrombosis or ischemia. It is predominately seen on the right ovary due to the possible effect of sigmoid colon in the left iliac fossa, which reduces the tubal structure motility. ${ }^{4}$ It is often found in reproductive age women and is found less in prepubertal and perimenopausal women. ${ }^{5}$

\section{CASE REPORT}

A 29 years old woman with four years history of primary infertility was on ovulation induction for natural timed intercourse in an outside center. Her BMI was normal and her antral follicle count on day 2 of her cycle was eight and seven. She was being administered with clomiphene tablets $50 \mathrm{mg}$ per day for first five days. The follicular growth was monitored by ultrasonography. On day eleven, left ovary with 2 follicles of 15 and $12 \mathrm{~mm}$ and right ovary with 3 follicles of $15 \mathrm{~mm}, 2$ follicles of 12 $\mathrm{mm}$ diameter were seen. Before the hCG trigger was given, on day 14 she was referred to us with persistent lower abdominal pain and three episodes of vomiting since morning. Ultrasonography performed in the outside center revealed enlarged right ovary with free fluid in pelvis which was suspected to be ovarian hyper stimulation syndrome. Analgesics and anti-emetics were administered before reaching our center. There was no pain relief in spite of analgesic administration.

The 2D ultrasonography at our center revealed enlarged right ovary $(8.77 \times 5.2 \mathrm{~cm})$ (Figure 1) and left ovary $(5.39 \times 3 \mathrm{~cm})$ (Figure 2$)$ with two corpus luteal cysts. The right ovary was located in midline superior to uterus. Colour doppler suggested enlarged cystic right ovary with heterogeneous echo texture and scanty stromal blood flow. Free fluid with low level internal echoes was observed and fluid was seen in Morison's pouch too. CT 
of abdomen revealed displaced hyperdense enlarged right ovary to midline with multiple peripherally arranged follicles (Figure 3) with dilated fallopian tube (Figure 4) and normal left ovary (Figure 5).

The blood investigations carried out suggested the following (Haemoglobin: $11 \mathrm{gm}$, total count: 16,000, viral markers: negative, creatinine: $0.5 \mathrm{mg} / \mathrm{dl}$, serum $\mathrm{E} 2: 1565 \mathrm{pg} / \mathrm{ml})$.

Emergency laparoscopy was performed and the findings were right ovary and tube twisted twice at in fundibulopelvic ligament (Figure 6), haemorrhagic right ovary (Figure 7) and hemoperitoneum of $250 \mathrm{ml}$ (Figure 8).

As it was not salvageable, the right ovary and tube were removed. Peritoneal lavage was given and port closure was done. Post operatively she was managed with IV fluids and GnRH antagonist.

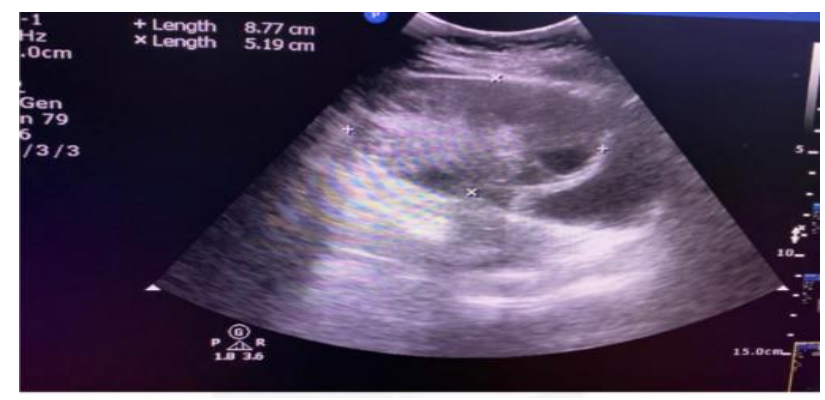

Figure 1: Ultrasonography of enlarged right ovary.

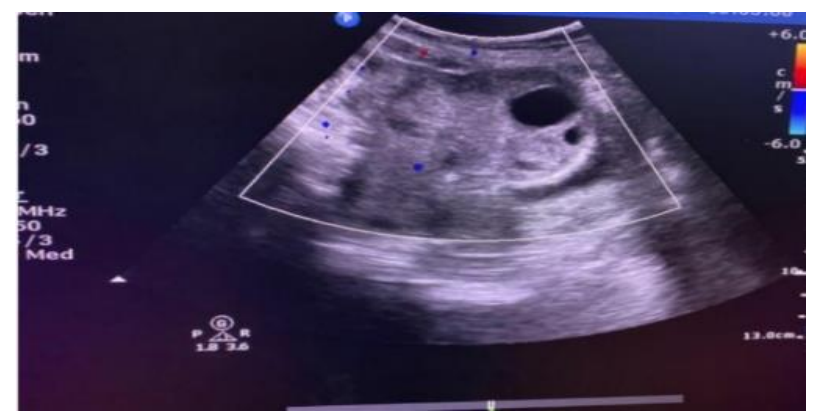

Figure 2: Ultrasonography of normal left ovary.

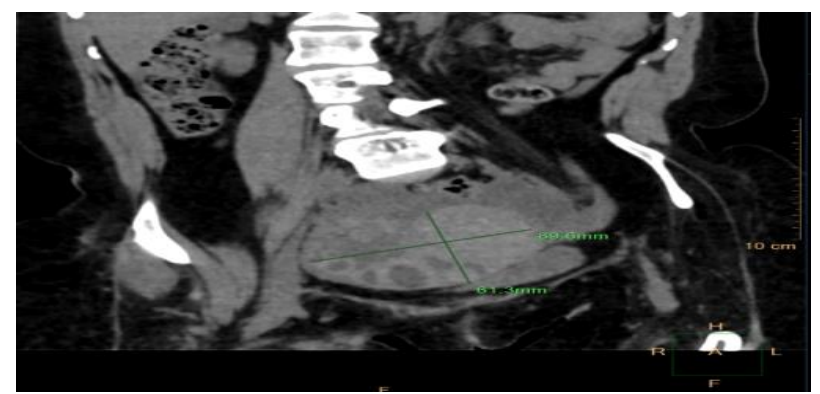

Figure 3: Non contrast CT abdomen coronal view of pelvis shows displaced hyperdense enlarged right ovary to mid line with multiple peripherally arranged follicles.

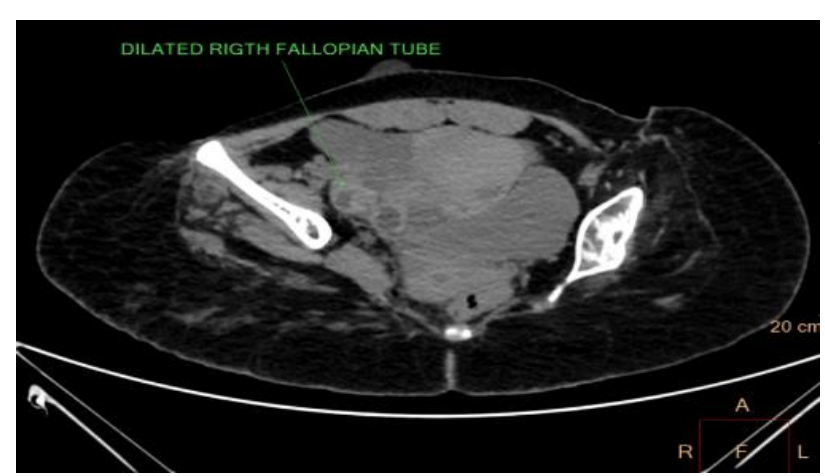

Figure 4: Non contrast CT abdomen of dilated fallopian tube.

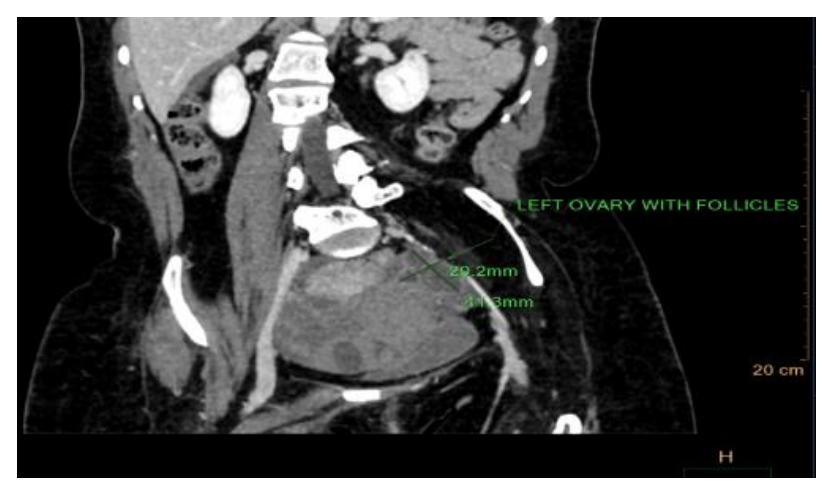

Figure 5: Non contrast CT abdomen coronal view of pelvis shows normal left ovary with follicles.

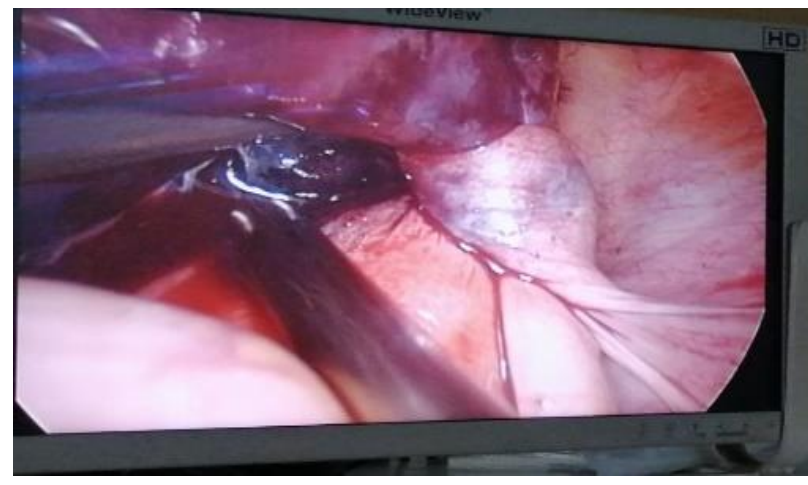

Figure 6: Twisted right tube and ovary.

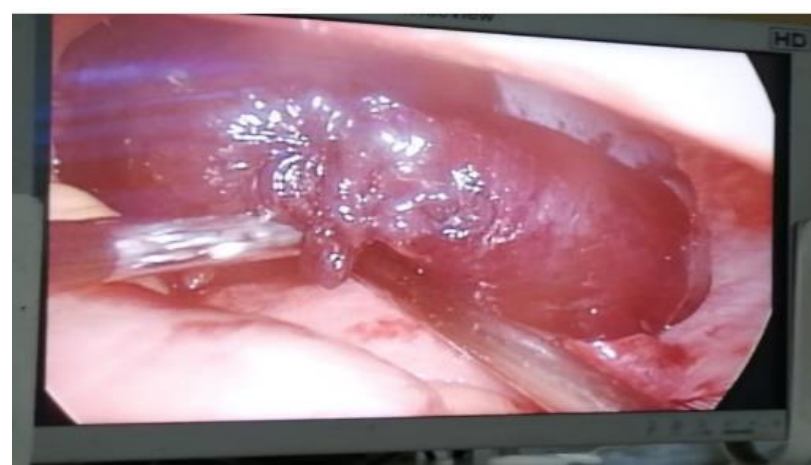

Figure 7: Haemorrhagic right ovary. 


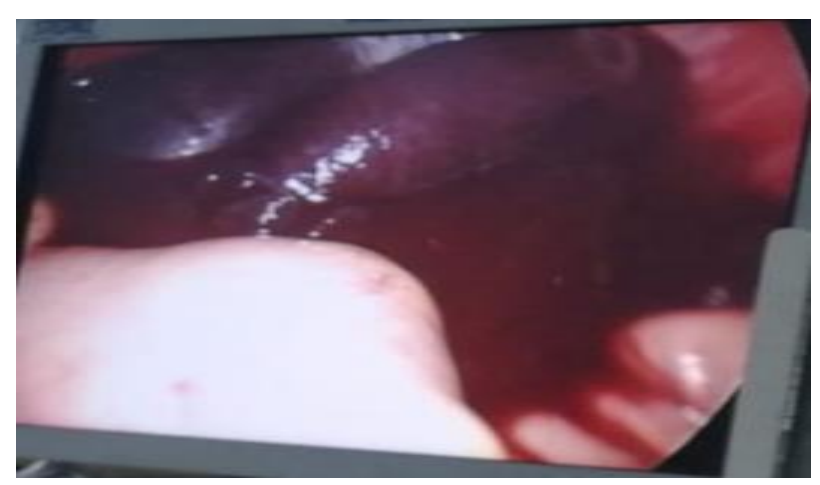

Figure 8: Hemoperitoneum.

\section{DISCUSSION}

Ovarian torsion is that needs to be included in the differential diagnosis of any girl with abdominal pain or a pelvic or abdominal mass. ${ }^{1}$ As the symptoms and signs are nonspecific it can be related to other clinical causes. ${ }^{6}$ Usually the presentations of ovarian torsion include abdominal pain, nausea, vomiting, fever and most common symptom is pain located in the lower abdominal region or pelvis which may radiate to the flank or thigh.,

Factors such as previous surgical history, a sudden change in body movement, and vigorous sexual intercourse have been reasons for adnexal torsion. Ovarian stimulation is also a recognized as one of the reasons for adnexal torsion, which can be explained by the increased volume and weight of the adnexa. ${ }^{7-10}$

It is reported that patients with ovarian hyperstimulation syndrome are the ones presenting the adnexal greatest volume and weight, which explains the increased risk of ovarian torsion. ${ }^{11}$ Though the complication is rare, it should always be considered as ovarian torsion occurs in $12-20 \%$ of the women with spontaneous OHSS. ${ }^{12-14}$ Ovarian hyper stimulation syndrome (OHSS) is generally characterized by enlargement of the ovaries and the formation of multiple cysts. Normally iatrogenic, OHSS occurs in the context of treatments for infertility and is extremely rare in spontaneous pregnancies. ${ }^{15}$ It is suggested that ovarian torsion should be suspected and ruled out in any female undergoing ovulation induction for IUI or IVF, presenting with severe abdominal pain. Delay in diagnosis and management could lead to ischemic necrosis of ovary. ${ }^{16}$

Clomiphene citrate is an orally active, non-steroidal triphenylethylene derivate which is commonly prescribed agent for ovulation induction. Clomiphene citrate is considered a safe agent and has rarely been associated with significant side effects. Ovarian hyperstimulation is seen mainly after gonadotropin therapy for ovulation induction and is very rarely associated with the use of clomiphene alone. ${ }^{17}$
It is suggested that diagnosis can usually be made on the basis of the characteristic clinical presentation in conjunction with ultrasound evidence of a unilaterally enlarged adnexal mass. ${ }^{18}$ It is also suggested that colour doppler sonography as a way to detect the absence of blood flow to the torsed ovary. ${ }^{19}$ Similarly, it is suggested that features that are better viewed with computed tomography (CT) or MRI that includes subacute ovarian hematoma and abnormal or absent ovarian enhancement. Other features of torsion such as ascites, deviation of the uterus to the side of the twist, engorged vessels on the twisted side, and fallopian tube thickening can also be revealed through $\mathrm{CT}$ or MRI. ${ }^{20}$

It is reported that conservative treatment involves untwisting the adnexa, with no adverse effect on fertility though there is theoretical fear of thromboembolic complications secondary to untwisting of ischaemic adnexa. ${ }^{21}$ It is reported that postoperative follow-up with ultrasound showed over $80 \%$ of patients had normal follicular development and retained normal ovarian function after detorsion. ${ }^{22}$

Other treatment options include simple ultra sound guided aspiration for treating a cystic ovary in torsion causing reduction in adnexal diameter, resulting in spontaneous untwisting. Laparoscopic aspiration of cysts and unwinding of ovary is also a treatment option. In a study, even in oedematous, partially necrotic ovary, torsion was untwisted, though the ovary remained oedematous and dark, partial ovariectomy was done. The residual gonad was fixed to the lateral pelvic side wall with multiple non-absorbable sutures. Patient was followed and 3 months later her FSH level did not elevate which confirmed residual ovarian function. 5.7 per cent of ovaries were atrophied without follicle development, where the ischemic insult to the ovary had been too severe to permit recovery. Higher postoperative pain scores and fever may predict a non-viable ovary. ${ }^{23}$

The gold standard to confirm and treat ovarian torsion is usually laparoscopy or laparotomy. Laparoscopy is a selective procedure with many benefits, including a lower risk of wound complications, less pain and postoperative ileus, shorter hospitalization, reduced adhesion formation, and quick recovery. ${ }^{24}$ Laparoscopy can be carried out in children and also in pregnant patients. ${ }^{25-27}$

\section{CONCLUSION}

Diagnosis of ovarian torsion continues to be a challenging task which requires awareness and a high degree of suspicion. The most consistent finding is a unilateral enlarged ovary, without which the diagnosis is unlikely to be ovarian torsion. The gynaecologist must be aware of the risks associated with the use of clomiphene citrate for infertility needs. Although adnexal torsion is rare, patients should be informed about this possible risk. 
Investigation for ovarian torsion should be made as one of the mandatory procedures for all the patients who undergo treatments for infertility presenting with abdominal pain as early diagnosis can be treated with minimum complications.

\section{Funding: No funding sources}

Conflict of interest: None declared

Ethical approval: Not required

\section{REFERENCES}

1. Cass DL. Ovarian torsion. In: Seminars in pediatric surgery. WB Saunders. 2005:86-92.

2. Hibbard LT. Adnexal torsion. Am J Obstet Gynecol. 1985;152:456-61.

3. White M, Stella J. Ovarian torsion: 10-year perspective. Emerg Med Australas. 2005;17:231-7.

4. Karaman E, Beger B, Çetin O, Melek M, Karaman Y. Ovarian torsion in the normal ovary: A diagnostic challenge in post menarchal adolescent girls in the emergency department. Med Sci Monit. 2017;23:1312-6.

5. Ding DC, Hsu S, Kao SP. Isolated torsion of the hydrosalpinx in a postmenopausal woman. JSLS. 2007;11:252-4

6. Tsafrir Z, Azem F, Hasson J, Solomon E, Almog B, Nagar $\mathrm{H}$ et al. Risk factors, symptoms, and treatment of ovarian torsion in children: The twelve-year experience of one center. J Minim Invasive Gynecol. 2012;19:29-33

7. Spero VL, Fritz Marc A. Clinical gynaecologic endocrinology and infertility. Lippincott Williams and Wilkins, Philadelphia. 2005;1183.

8. Mashiach S, Bider D, Moran O, Goldenberg M, BenRafael Z. Adnexal torsion of hyperstimulated ovaries in pregnancies after gonadotropin therapy. Fertil Steril. 1990;53:76-80.

9. Bider D, Goldenberg M, Ben-Rafael Z, Oelsner G. Bilateral adnexal torsion after clomiphene citrate therapy. Hum Reprod. 1991;6:1443-4.

10. Shalev E, Peleg D. Laparoscopic treatment of adnexal torsion. Surg Gynecol Obstet. 1993;176:44850 .

11. Huchon C, Fauconnier A. Adnexal torsion: a literature review. Eur J Obst Gynecol Reprod Biol. 2010;150:8-12.

12. Carlo D, Savoia F, Fabozzi A, Gargano V, Nappi C. A case of ovarian torsionin a patient carrier of a FSH receptor gene mutation previously affected by spontaneous ovarian hyperstimulation syndrome. Gynecol Endocrinol. 2015;31:105-8.

13. Munshi S, Patel A, Banker M, Patel P. Laparoscopic detorsion for bilateralovarian torsion in a singleton pregnancy with spontaneous ovarianhyperstimulation syndrome. J Hum Reprod Sci. 2014:7:66-8.

14. Dey AK, Dubey A, Mittal K, Kale S, Spontaneous ovarian hyperstimulation syndrome understanding the dilemma. Gynecol Endocrinol. 2015;20:1-3.

15. Navarro NG, Grau EG, Pérez SP, Luna LR. Ovarian torsion and spontaneous ovarian hyperstimulation syndrome in a twin pregnancy: a case report. Int $\mathrm{j}$ surg case reports. 2017;34:66-8.

16. Krishnan S, Kaur H, Bali J, Rao K. Ovarian torsion in infertility management-Missing the diagnosis means losing the ovary: A high price to pay. J Hum Reprod Sci. 2011;4:39.

17. Shiau CS, Huang YH, Chang MY, Lo LM, Hsieh CL. Adnexal torsion in a woman undergoing ovarian hyperstimulation with clomiphene citrate therapy: a case report and review of the literature. Arch Gynecol Obstet. 2012;285:271-3.

18. Kolluru V, Gurumurthy R, Vellanki V, Gururaj D. Torsion of ovarian cyst during pregnancy: a case report. Cases J. 2009;2:9405.

19. Peña JE, Ufberg D, Cooney N, Denis AL. Usefulness of Doppler sonography in the diagnosis of ovarian torsion. Fertil Steril. 2000;73:1047-50.

20. Kimura I, Togashi K, Kawakami S, Takakura K, Mori T, Konishi J. Ovarian torsion: CT and MR imaging appearances. Radiol. 1994;190:337-41.

21. Oelsner G, Shashar D. Adnexal torsion. Clin Obstet Gynecol. 2006;49:459-63.

22. Huang $\mathrm{C}$, Hong MK, Ding DC. A review of ovary torsion. Tzu-chi Med J. 2017;29:143.

23. Dolgin SE, Lublin M, Shlasko E. Maximizing ovarian salvage when treating idiopathic adnexal torsion. J Pediatr Surg. 2000;35:624-6.

24. Pramana C, Monica I, Rizkika O, Dewanti IZF, Andriani DY, Eka R. Ovarian Cyst Torsion: a Case Report. Int J Med Rev Case Rep. 2020:4:44-6.

25. Steyaert H, Meynol F, Valla JS. Torsion of the adnexa in children: the value of laparoscopy. Pediatr Surg Int 1998;13:384-7.

26. Wolfman WL, Kreutner K. Laparoscopy in children and adolescents. J Adolesc Health Care. 1984;5:2615 .

27. Bassil S, Steinhart U, Donnez J. Successful laparoscopic management of adnexal torsion during week 25 of a twin pregnancy. Hum Reprod. 1999; 14:855-7.

28. Chang HC, Bhatt S, Dogra VS. Pearls and pitfalls in diagnosis of ovarian torsion. Radiograph. 2008;28:1355-68.

Cite this article as: Swapna Y, Elanchezhian M, Chegireddy S, Badipati R, Devadharshini V. Ovarian torsion in infertility treatment. Int J Reprod Contracept Obstet Gynecol 2021;10:787-90. 